
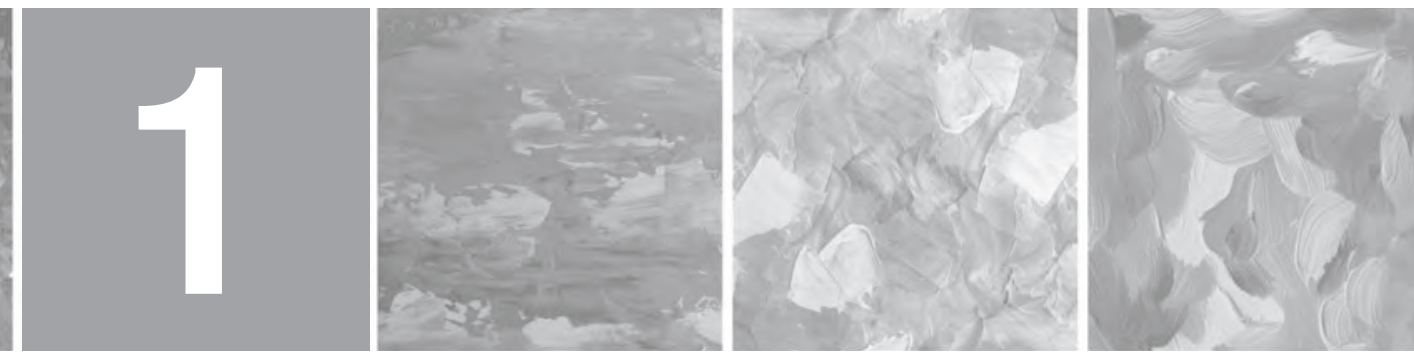

\title{
OVERVIEW OF PATIENT SAFETY AND QUALITY OF CARE
}

Ronda G. Hughes

It is, I guess, politically correct, widely believed, that to say that American health care is the best in the world. It's not. (Berwick, 2009)

\section{Upon completion of this chapter, the reader should be able to}

1. Define quality of care and patient safety.

2. Discuss key terms used to define quality of care and patient safety.

3. Identify national healthcare organizations influencing quality and safety.

4. Discuss measuring quality and safety.

5. Discuss core measures, sentinel events, and never events.

6. Discuss healthcare quality and safety in industrialized countries.

7. Describe the costs of achieving patient safety and quality of care.

8. Describe key programs that recognize hospital excellence.

9. Discuss the influence of the Institute of Medicine's (IOM) Quality Chasm series of reports.

10. Discuss the role of nurses at the "sharp" end of healthcare.

11. Discuss efforts to increase healthcare transparency, improve public reporting of healthcare, and reduce unwarranted variation in healthcare safety and quality. 
A patient, Mr. R., was admitted to the hospital with uncontrollable pain from a kidney stone. He also had a history of sleep apnea. The nursing unit was short staffed that night and each nurse was busy, taking care of more patients than normal. Mr. R., who was a tall, overweight, 46-year-old man, kept asking for additional intravenous pain medication as he walked around the unit to try to ease the pain. The nurse called the physician to increase the dose of the pain medication. The physician ordered the increase and the nurse on the next shift proceeded to administer the higher dose without looking at how much pain medication Mr. R. had already received in the past 12 hours, nor did the nurse look at his health history. An hour later, Mr. R. told his nurse that he finally had some pain relief and he was going to his room to see if he could sleep for a few hours. His nurse, busy with other patients, went to check on Mr. R. 3 hours later. She found Mr. R. in his bed, cold to the touch with no respirations. He had been dead for 2 hours by the time the nurse went to check on him. With the combination of what ended up being too high of a dose of the pain medication (a medication known to be associated with life-threatening respiratory depression), the patient's history of sleep apnea, and the fact that the nurse did not assess her patient during a 3-hour period, the nurse, the physician, and the hospital were sued for malpractice by the family.

1. What should the nurse have done prior to administering the last dose of the pain medication?

2. What should the nurse have done after administering the last dose of the pain medication?

3. What should the nurse, physician, and hospital have done to assist the nurse in avoiding the medication error?

During the past 20 years, our nation has been focused on improving healthcare outcomes for patients and their families through improving the quality and safety of care. Concerns about rising healthcare costs, difficulty in accessing care, and healthcare research have highlighted the need for improving healthcare, and national initiatives have been implemented to accelerate change. However, improvements in quality and safety have been slow. These improvements can be slowed by the complexity of healthcare and the everyday challenges and opportunities of ensuring that the care available to and accessed by patients and their families reflects high quality and is safe. This slow improvement in quality and safety could be considered outrageous, especially considering how much is spent on healthcare in the United States, more than any other country in the world.

Frontline bedside nurses, as well as all nurses, have a significant leadership role to play in patient care. They have a significant influence on the incidence of patient falls, pressure ulcers, nosocomial infections, pain management, quality improvement (QI), and safety. Nurses influence patient satisfaction, mortality and morbidity rates, lengths of stay, complications, and so on. When a patient is at risk for a problem, it is often the bedside nurse who alerts the interprofessional team and begins the problemsolving process on behalf of patients.

This chapter provides an overview of the key concepts, drivers, and strategies for improving the quality of care and patient safety. Specifically, it begins with an overview of key terms used to define quality of care and patient safety, followed by key factors that influence healthcare safety and quality including the role of national healthcare accreditation organizations. The chapter then provides an overview of core measures, sentinel events, and never events. Since healthcare and patient safety issues are occurring worldwide, the chapter also includes an overview of quality and safety in industrialized countries. The chapter then provides a discussion of the costs of achieving patient safety and quality of care, and the key programs that recognize 
hospital excellence. This is followed by an overview of the influence of the Institute of Medicine's (IOM) Quality Chasm series of reports and how the role of nurses puts them at the "sharp end" of healthcare in direct contact with patients. The chapter concludes with an overview of efforts to increase healthcare transparency, improve public reporting of healthcare, and reduce unwarranted variation in healthcare safety and quality.

\section{QUALITY OF CARE AND PATIENT SAFETY}

The IOM considers patient safety both "indistinguishable from the delivery of quality health care" (Aspden, Corrigan, Wolcott, \& Erickson, 2004), and the foundation of healthcare quality (Committee on the Quality of Health Care in America, 2001). Leaders in the United States have emphasized the need to redesign systems of care to better serve patients in the complex environment of our healthcare system. This has included efforts to inform policy through national policy reports, such as the IOM Quality Chasm series of reports (IOM, 1999, 2001), healthcare research and evaluation, and both federal and state policy changes to accelerate safety and QIs. Federal and state regulatory agencies have implemented new quality and safety requirements and financial penalties for poor quality care and care that has harmed patients. There have also been several national initiatives to improve quality and safety, such as the Institute for Healthcare Improvement's (IHI) Transforming Care at the Bedside (IHI, 2017a), 5 Million Lives Campaign (IHI, 2017b), and the Triple Aim (IHI, 2017c). The Centers for Medicare and Medicaid Services (CMS) have also stopped reimbursement for extra healthcare costs associated with events that harm patients that are considered preventable. Yet, despite these many efforts, both government agencies, such as the Agency for Healthcare Research and Quality (AHRQ), and national healthcare quality organizations, such as the Leapfrog Group, report that there have been some improvements in quality and safety, but disparities and problems with quality and safety persist (AHRQ, 2011; The Leapfrog Group, 2017).

\section{KEY TERMS USED WITH QUALITY AND SAFETY}

Healthcare quality is defined as "the degree to which healthcare services for individuals and populations increase the likelihood of desired health outcomes and are consistent with current professional knowledge" (IOM, 2001). High-quality care is defined as care that is safe, timely, effective, efficient, equitable, and patient centered (also referred to as STEEEP) with no disparities between racial or ethnic groups (IOM, 2001). AHRQ expanded the definition of quality to include, "doing the right thing, at the right time, in the right way, to achieve the best possible results" (AHRQ, 2011). The IOM has recommended that quality can be improved on four levels:

- The patient level

- The health-delivery "microsystems" level, such as a surgical team or acute-care unit

- The organizational level, such as hospitals and healthcare systems

- The regulatory and financial environment level in which those organizations operate (IOM, 2001) 
Errors are defined as "an act of commission (doing something wrong) or omission (failing to do the right thing) leading to an undesirable outcome or significant potential for such an outcome" (Wilson, Harrison, Gibberd, \& Hamilton, 1999). Unfortunately, most errors in healthcare are viewed as a reflection of an individual's lack of knowledge or skill. Thus, when an error occurs, you will see efforts to blame or punish an individual. Yet, when considering the context in which healthcare errors occur, errors are usually a reflection of human failings within poorly designed systems. From this systems perspective, after an error occurs, we must try to identify factors that most likely led to the error and find solutions and changes to current healthcare processes so that we can reduce the possibility of a recurrence of the error or reduce the impact of the error on patients.

An adverse event, which may be considered either preventable or not, is defined as any undesirable experience in which harm resulted to a person receiving healthcare that "requires additional monitoring, treatment, or hospitalization, or that results in death" (IOM, 1999). Preventable adverse events are considered to reflect care that falls below the standard of care. Serious preventable adverse events are generally defined as an adverse event that is preventable and results in a patient death, loss of a body part, disability, or loss of bodily function lasting for more than 7 days or still present at the time of discharge. The U.S. Food and Drug Administration (FDA), expands this definition to focus on any undesirable experience associated with a medical product, such as a medication or medical device. In such instances, the undesirable experience is considered an adverse event and should be reported to the FDA when, for example, the patient:

- Dies

- Experiences a life-threatening reaction

- Has an initial or prolonged hospitalization resulting from the adverse event

- Experiences "significant, persistent or permanent change, impairment, damage or disruption" of normal function

- Needs a "medical or surgical intervention" because of an adverse event (FDA, 2016)

When there are problems or an adverse event occurs with any medication or medical device, health professionals and consumers/patients can report the event online via the FDA Adverse Event Reporting System (FAERS) (www.fda.gov/Drugs/ GuidanceComplianceRegulatoryInformation/Surveillance/AdverseDrugEffects / default.htm) or MedWatch (www.fda.gov/Safety/MedWatch/default.htm). Adverse events can also be reported to the organization where the event took place through incident reporting systems, if appropriate, and/or to a state adverse event reporting system or health department, depending on the state.

Sentinel events (sometimes referred to "never events" or "serious reportable events") are defined as any unanticipated event in a healthcare setting that reaches a patient and results in any of the following:

- Death

- Permanent harm

- Severe temporary harm and intervention required to sustain life (The Joint Commission [TJC], 2017a)

When a sentinel event occurs that results in death or serious physical or psychological injury to a patient that is not related to the natural course of the patient's illness, it should be (but is not required to be) reported first within the organization according to policy because these types of events, which are rare occurrences, should never 
TABLE 1.1 SENTINEL EVENT DATA, 2014 TO SECOND QUARTER, 2017

\begin{tabular}{ll}
\hline Retention of foreign body & 400 sentinel events \\
Wrong-site surgery & 325 sentinel events \\
Fall & 300 sentinel events \\
Suicide & 300 sentinel events \\
Delay in treatment & 250 sentinel events \\
Operative/postoperative complication & 150 sentinel events \\
Criminal event & 100 sentinel events \\
Medication error & 100 sentinel events \\
Perinatal death/injury & 100 sentinel events \\
\hline
\end{tabular}

Numbers are approximate. The reporting of most sentinel events to TJC is voluntary.

Source: The Joint Commission. (2017). Sentinel event data general information 202017 Update. Retrieved from

www.jointcommission.org/assets/1/18/General_Information_2Q_2017.pdf

happen. There are 29 types of sentinel events/serious reportable events (the full list is available at http://www.qualityforum.org/Topics/SREs/List_of_SREs.aspx), including:

- Surgery on the wrong patient, at the wrong site, or a wrong procedure surgery

- Suicide in a hospital or within 72 hours of discharge

- Falls

- Delay in treatment

- Medication errors

- Surgical instrument or object left in a patient after a surgery or other procedure (National Quality Forum [NQF], 2017)

When a sentinel event occurs, the healthcare organization is "strongly encouraged," but not required, to report the sentinel event to The Joint Commission (TJC) and is "expected to conduct thorough and credible comprehensive systematic analyses (e.g., root cause analyses), make improvements to reduce risk, and monitor the effectiveness of those improvements" (TJC, 2017b). Patients, family members, staff, and the media can also report patient safety events to TJC. Note that the reporting of most sentinel events to TJC is voluntary and represents only a small proportion of actual events (Table 1.1).

\section{CAUSES OF ERRORS}

Everyone can make mistakes. Errors in providing healthcare to patients and their families are caused by a variety of factors, such as incompetency, lack of education or experience, inaccurate documentation, language barriers, fatigue, and inadequate communication among clinicians (Weingart, Wilson, Gibberd, \& Harrison, 2000). Errors are also associated with extremes of age, new procedures, urgent conditions, and the severity of the medical condition being treated (Palmieri, DeLucia, Ott, Peterson, \& Green, 2008).

\section{NATIONAL HEALTHCARE ORGANIZATIONS INFLUENCING QUALITY AND SAFETY}

While the initial estimates in the IOM's To Err Is Human report proclaimed that each year there were about 98,000 preventable deaths, recent research by Makary and Daniel (2016) has found that more than 250,000 deaths each year are the result of 
errors within healthcare. That means that after heart disease and cancer, patient safety errors are the third leading cause of death in the United States (Makary \& Daniel, 2016). Recognizing these and other challenges within healthcare, national healthcare organizations provide resources and incentives to improve quality of care and patient safety.

There are three key agencies within the U.S. Department of Health and Human Services that are influential in encouraging improvements in healthcare quality and patient safety. These agencies include AHRQ, CMS, and FDA. The AHRQ (www. ahrq.gov) is focused on producing evidence to make healthcare safer, higher quality, more accessible, and equitable, and working to make sure that evidence is understood and used. The CMS (www.cms.gov) has multiple roles in influencing the quality of care and patient safety. The CMS works with both public and private organizations to ensure quality care, promote efficient health outcomes, and make sure that CMS policies are used by healthcare organizations and clinicians to receive reimbursement payments for their services to improve patient outcomes. The FDA (www.fda.gov) is responsible for protecting the public health by ensuring the safety, efficacy, and security of human and veterinary drugs, biological products, and medical devices; and by ensuring the safety of our nation's food supply, cosmetics, and products that emit radiation (FDA, 2017).

Several organizations, particularly the organizations listed in the following section, have significant roles in influencing the quality of care and patient safety. These organizations influence healthcare safety and quality by working with government organizations, healthcare organizations, and healthcare clinicians, as well as accreditation organizations:

- The Institute for Safe Medication Practices (ISMP) is a private nonprofit organization that leads efforts to improve how medications are used by preventing medication errors and promoting safe medication use, through its national Medication Errors Reporting Program, which collects medication error reports from healthcare professionals, and the Medical Error Recognition and Revision Strategies program, where ISMP works directly and confidentially with pharmaceutical companies to prevent errors associated with confusing or misleading medication naming, labeling, packaging, and device design (www.ISMP.org).

- The National Academy of Medicine (NAM), formerly the IOM, provides peerreviewed evidence-based information and advice concerning health and health policy issues. The NAM released a series of 11 reports on quality and patient safety, starting with its seminal report, To Err is Human: Building a Safer Health System (IOM, 1999), followed by Crossing the Quality Chasm (IOM, 2001). The IOM also released the report, The Future of Nursing: Leading Change, Advancing Health, which sets forth a series of recommendations for nursing to have a greater role in the complex U.S. healthcare system (IOM, 2013).

- The National Quality Forum (NQF) is a private nonprofit organization that conducts review processes and works with stakeholders to standardize healthcare performance measures. NQF has certified 34 separate healthcare practices and procedures to be effective in reducing the occurrence of adverse events. A National Priorities Partnership, convened by the NQF, has issued sets of specific actions to reduce healthcare costs in three important areas, i.e., avoiding hospital readmissions, reducing emergency department overuse, and preventing medication errors (www.qualityforum.org). 
- IHI is a private nonprofit organization that motivates and builds the will for change, partnering with patients and healthcare professionals to test new models of care and ensuring the broadest adoption of best practices and effective innovations (www.ihi.org).

- TJC, formerly named the Joint Commission on Accreditation of Healthcare Organizations, is a private nonprofit organization that operates accreditation programs for a fee to subscriber hospitals and other healthcare organizations. Generally, TJC ensures that quality compliance requirements are met, including core measures, safe practice measures, and process improvement efforts to accredit a hospital. It is also known for its standards and tools aimed at ensuring quality of care and patient safety, such as the Sentinel Event Policy, Improving the Root Cause Analyses and Actions (RCA2) methodologies and techniques, and the National Patient Safety Goals (www.JointCommission.org).

- The Leapfrog Group is a private nonprofit organization that collects and reports its Leapfrog Hospital Survey on hospital performance to improve the value of care and, through its Leapfrog Hospital Safety Grade, assigns letter grades to hospitals based on how they perform on patient safety measures (www. leapfroggroup.org).

- Healthcare Financial Management Association (HFMA) represents leaders in healthcare finance with broad-based stakeholders in healthcare to provide education and coalition building to improve healthcare through best practices and standards. Through its Value Project, HFMA identified patient quality concerns including "access, make my care available and affordable; safety, don't hurt me; outcomes, make me better; and respect, respect me as person, not a case" (HFMA, 2015; Table 1.2)

There are also some efforts to collect and provide information on performance measurement data to consumers, physicians, and others. Data from CMS Hospital Compare provides information on the quality of care provided to patients at hospitals. The information that enables consumers to compare hospitals, which can be accessed at, www.medicare.gov/hospitalcompare, is organized into several categories, including

- Survey of patients' experiences (Hospital Consumer Assessment of Healthcare Providers and Systems [HCAHPS])

- Timely and effective care

- Complications

- Readmissions and deaths

- Use of medical imaging

- Payment and value of care (CMS, 2017a)

TABLE 1.2 PATIENT QUALITY CONCERNS

\begin{tabular}{ll} 
ACCESS & MAKE MY CARE AVAILABLE AND AFFORDABLE \\
Safety & Do not hurt me \\
Outcomes & Make me better \\
Respect & Respect me as person, not a case \\
\hline
\end{tabular}

Source: Healthcare Financial Management Association (HFMA). (2015). Value in health care: Current state and future directions. Westchester, IL: Healthcare Financial Management Association. Retrieved from http://www.hfma.org/valueproject/valuesourcebook/ 


\section{CASE STUDY 1.1}

The case manager at a community hospital was reviewing occurrence report data trends over the last quarter. There appeared to be an increasing trend of patients who are not appropriate candidates for an MRI due to the patients having implanted metal devices. The lead MRI technologist is very concerned that these patients are not being correctly screened by the nurses on the unit.

The risk manager put together an interprofessional team from the nursing, medical, and MRI departments. After reviewing the MRI screening process, it was discovered that a new scheduling system that had been put in place in the radiology department was so efficient at getting patients an MRI appointment, the unit nurses did not have time to complete an MRI patient screening after the doctor had ordered it. A new MRI screening process was immediately implemented. The MRI order would now not be placed by the unit secretary until the RN communicated that the MRI patient screening was completed. Note that the problem reported by MRI staff led to the work process change. This protected patients from a potential injury.

1. Why is it important that patients with implants be identified on the unit by the nurse rather than later by the MRI technologist?

2. How did the Risk Management process of reviewing the MRI screening process help with this patient safety issue?

\section{MEASURING QUALITY AND SAFETY}

Work by the AHRQ, CMS, and NQF has led the development of measures for improving the quality of care and patient safety. Many of these measures depend on the occurrence of adverse patient outcomes or injury (measures of patient safety) while others raise the standard of care by ensuring that recommended care is available and used by all patients at the right time (measures of quality of care). When considered together, these measures can help healthcare organizations improve the value of care they provide to all patients.

There are several examples of quality care and patient safety measures that are used primarily in healthcare organizations, such as hospitals, nursing homes, and outpatient clinics. The major sets of measures include the CMS Core Measures, AHRQ Quality Indicators, AHRQ Patient Safety Indicators, NQF and American Nurses Association (ANA) Nurse Sensitive Indicators, and the National Committee for Quality Assurance (NCQA) Healthcare Effectiveness Data and Information Set (HEDIS) Measures (Table 1.3). Many professional organizations and other healthcare organizations also have quality of care and patient safety measures that can be found through websites of professional organizations and in peer-reviewed journal publications. 
TABLE 1.3 EXAMPLES OF MEASURES OF PATIENT SAFETY AND MEASURES OF QUALITY OF CARE

MEASURE SET

Core Measures (CMS, 2017b)

- Used to improve quality of care for common conditions

- www.cms.gov/ Medicare/QualityInitiatives-PatientAssessmentInstruments/ QualityMeasures/CoreMeasures.html

- www.cms.gov/ Medicare/QualityInitiatives-PatientAssessmentInstruments/ QualityMeasures/CoreMeasures.html

\section{Patient Safety} Indicators (AHRQ, 2017a)

- Used to improve the safety of inpatient care

- www.qualityindicators. ahrq.gov/modules/ psi_overview.aspx

\section{A FEW EXAMPLES OF THE MEASURES}

- Stroke: Received medication to prevent blood clots

- Immunization: Assessed for flu vaccine

- Heart failure: Received beta blocker therapy for left ventricular systolic dysfunction

- Age appropriate screening colonoscopy

- Readmission: All-cause readmission rate following elective total hip or total knee replacement
- Rate of pressure ulcers

- Retained surgical item or unretrieved device fragment count

- Rate of central venous catheterrelated blood stream infections

- Rate of postoperative sepsis

- Transfusion reaction count

- Rate of accidental punctures or lacerations

- Rate of birth trauma-injury to neonate

\section{Prevention Quality Indicators}

- Perforated appendix admission rate (AHRQ, 2017b)

- Used to improve quality of care

- qualityindicators.ahrq. gov
- Hypertension admission rate

- Urinary tract infection admission rate

- Uncontrolled diabetes admission rate

- Bacterial pneumonia admission rate Inpatient Quality Indicators

- Hip replacement mortality rate

- Heart failure mortality rate

- Acute stroke mortality rate

- Laparoscopic cholecystectomy rate

- Hysterectomy rate

\section{WHERE USED}

- Hospitals

- Health plan/ integrated delivery systems

- Individual clinician level
Hospitals

Hospitals

Hospitals

(continued) 
TABLE 1.3 EXAMPLES OF MEASURES OF PATIENT SAFETY AND MEASURES OF QUALITY OF CARE (continued)

MEASURE SET

Nurse Sensitive

Indicators (ANA, 2010; NQF, 2004)

- Used to improve the quality of nursing care

- www.qualityforum. org/improving_care_ through_nursing.aspx

HEDIS (NCQA, 2017)

- Used to measure performance in care and services

- www.ncqa.org/hedisquality-measurement/ hedis-measures

\section{URAC}

- Used to assess QI with organizations

- www.urac.org/ standards-andmeasures-glance

\section{A FEW EXAMPLES OF THE MEASURES}

Pediatric Quality Indicators

- Neonatal mortality

- Pressure ulcers

- Transfusion reactions

- Postoperative hemorrhage or hematoma

- Postoperative respiratory failure

- Falls with injury

- Nursing care hours per patient day

- Pressure ulcers

- Rate of nosocomial infections

- Staffing mix (ratios of RNs, LPNs, and unlicensed staff)

- Childhood immunizations status

- Colorectal cancer screening

- Medication management for people with asthma

- Controlling high blood pressure

- Annual dental visit

- Patient and family member engagement

- Effectiveness of communications and service coordination between providers and across providers and their patients

- Errors and infections associated with harm and death
WHERE USED

Hospitals

Hospitals

- Outpatient clinics and offices

- Other organizations (e.g., health insurance company)

- Variety of healthcare programs (e.g., healthcare management programs, provider integration and coordination programs)

HEDIS, Healthcare Effectiveness Data and Information Set; LPN, licensed practical nurse; URAC, Utilization Review Accreditation Commission.

\section{CRITICAL THINKING 1.1}

Each year, hospitals, healthcare systems, and healthcare providers report quality measures to national organizations. They also use these measures to assess their overall performance and they generally group these quality measures into several key strategic areas:

- Quality and safety of care

- Patient satisfaction/experience

- Workforce issues 


\section{CRITICAL THINKING 1.1 (continued)}

- Financial performance

- Strategic sustainability and growth)

Explore one of the websites in Table 1.3 for one of the measures described there. Think about how nurses can use these measures to improve nursing care and patient outcomes in these five key strategic areas.

1. How can nursing care and patient outcomes be improved by reviewing patient satisfaction measures?

2. How can nursing care and patient outcomes be improved by reviewing quality and safety of care?

\section{UNWANTED VARIATION IN HEALTHCARE QUALITY AND SAFETY}

Unwanted variation is variation in the use of medical care that cannot be explained on the basis of illness, medical evidence, or patient preferences, Wennberg, as reported by McCue (2003) has categorized four types of variation:

- Variations from the underuse of effective treatments or intervention that has been shown in clinical studies to improve health status or quality of life, for example, the use of beta blockers postmyocardial infarction

- Variations in outcomes attributable to the quality of care, for example, increased mortality following surgery

- Variations from the misuse of preference-sensitive services, for example, hysterectomy versus hormone treatment

- Variations from the overuse of supply-sensitive services, for example supplies that are overused because they are easily available to patients and healthcare practitioners, for example, medications and various technologies

There is variation in healthcare in various areas of the United States, variation provided by different healthcare providers and agencies, and variation in services available to different socioeconomic groups. There is also significant variation in what healthcare providers charge for different services. Nurses and the interprofessional team must work to reduce variation and improve healthcare service delivery to all patients.

\section{TRANSPARENCY AND REPORTING PERFORMANCE}

Healthcare clinicians, insurance companies, state and federal governments, patients and their families, and many others have the opportunity to improve patient safety and the quality of healthcare. National and state efforts to motivate improvements in healthcare have included financial incentives, regulation, accreditation, and public reporting. Of these, public reporting of performance is thought to be the best motivator for improving patient safety and quality of care. When organizations and clinicians are transparent in reporting their performance against quality measures, it is believed that they are being accountable, that they ethically respond to failures (Leape, 2010), and that they are 
informing consumer choice (Berwick, James, \& Coye, 2003). In most instances, transparency is considered to include reporting not only the real cost of care, but also clearly reporting information about performance failures as well as successes (Pronovost et al., 2016). Major domains of healthcare transparency include the following:

- Clinical quality

- Resource use

- Efficiency

- Patient experience of care

- Professionalism

- Healthcare system/facility recognition and accreditations for meeting national standards

- Financial relationship of physicians and other healthcare professionals

- Financial relationship between physicians and other healthcare professionals, and industry

- Health insurance company processes (American College of Physicians [ACP], 2010)

Improvement of how care is delivered and improvement in patient outcomes from care received is a labor-intensive process that uses many staff and financial resources. Improvement processes include accurately looking at errors that occur from providing care; looking at areas where the quality of care can be improved through the early detection, prevention, and reporting of errors; and looking at improving performance on measures of quality care. Yet reporting errors or problems in quality of care is not straightforward. Federal and state governments, as well as private organizations have used mandatory reporting systems for errors and instances of poor quality of care, yet they are often not effective because of the fear that clinicians have of being punished, for example, with financial fines or punitive actions. As a result, errors continue to be underreported.

In many states, when a serious preventable adverse event occurs in a healthcare facility, for example, a hospital, nursing home, and so on, that is licensed by a state government, the facility is required by state law to report the event to their state government. However, it is important to note that while the majority of states have this requirement, not all states require this. TJC also has a voluntary reporting system.

Relatedly, it is also important to report successes and achievements in patient safety and quality of care within an organization. For example, reports of positive nursing sensitive indicators of high-quality care include achievement of appropriate self-care, demonstration of health-promoting behaviors, achievement of positive health-related quality of life, perception of being well cared for, and good symptom management. Mortality (i.e., death), morbidity (i.e., disease), and adverse events are considered negative outcomes by both clinicians and external organizations. Reporting successes can be helpful in understanding if an organization or clinicians are able to sustain and attain goals in safety and quality.

Patient safety and quality of care can improve in organizations committed to safety and quality throughout the organization. Unfortunately, not all organizations are committed to improving patient safety and quality. Nurses report that there is a lack of a blame-free environment and problems with leadership support to establish and maintaining a culture of safety (Wolf \& Hughes, 2008). The barriers for attaining a culture of safety include lack of leadership, a culture where low expectations prevail, poor teamwork, and poor communication. Optimally, everyone, at all levels within an organization, would work in a culture of safety where there is

- Acknowledgment of the high-risk nature of an organization's activities and the determination to achieve consistently safe operations 
- A preoccupation with safety

- An emphasis on systems improvement to support performance

- Organizational commitment of resources and encouragement of collaboration across ranks and disciplines to seek solutions to patient safety concerns

- Encouragement of collaboration to find solutions for patient safety problems

- Proactive reporting of unsafe conditions

- A just culture (or culture of justice) response to error, which includes frequent debriefing and sharing of "lessons learned," and which has an atmosphere of teamwork within a blame-free environment with mutual respect, which enables candid discussion among employees, where patient safety concerns are dealt with quickly (AHRQ, 2017c)

Safety culture is generally measured by surveys of providers at all levels. Available validated surveys include AHRQ's Patient Safety Culture Surveys (available at psnet. ahrq.gov/resources/resource/5333) and the Safety Attitudes Questionnaire (available at psnet.ahrq.gov/resources/resource/3601).

\section{THE CONSEQUENCES OF WHEN THINGS GO WRONG}

Errors in healthcare that harm patients cost approximately $\$ 17.1$ billion each year (Van Den Bos et al., 2011). It has been estimated that, while hospitalized, about one in four patients experience one or more adverse events that result in a longer hospital stay, permanent harm, the need for a life-sustaining intervention, or death. Of these adverse events that resulted in injury, almost half were preventable (Office of the Inspector General [OIG], 2010).

Errors happen because of a multitude of factors, such as lack of education or experience, misdiagnosis, under-and over-treatment, urgency, and fatigue (IOM, 1999). Patient harm during a hospitalization is also impacted by nurses. The more times a hospitalized patient is exposed to below targeted nurse staffing levels, the greater the risk for patient mortality (Needleman et al., 2011). While nurses are capable of preventing the majority of errors from harming a patient, all errors need to be reported (Wolf \& Hughes, 2008) by the members of the healthcare team, not just nurses. The team needs to work together to mitigate (or minimize the amount of) the effects of an error for the patient.

As part of national efforts to reform Medicare, and in an effort to encourage hospitals to improve the quality and safety of care, CMS and many private insurance companies require hospitals to report the occurrence of sentinel events and will apply a financial penalty to the hospital if and when sentinel events do occur. Sentinel events (e.g., mortality, readmissions within 30-days of discharge, and wrong-site surgery) are considered to be preventable and should not happen. When they do happen, the hospital will not be reimbursed for the cost of care associated with the cost of care for the aftermath of the sentinel event (e.g., longer hospital stays, a corrective surgical procedure) from CMS. CMS (and now many private insurance companies) will also not pay for conditions related to Never Events, including:

- Certain serious pressure ulcers

- Acquired urinary tract infections from catheter use

- Acquired blood stream infections from catheters

- Air embolism

- Giving the wrong blood type

- Foreign objects left in surgical patients (CMS, 2008) 
In some instances, errors that cause patient harm result in a medical malpractice lawsuit. Approximately $\$ 55.6$ billion in 2008 or $2.4 \%$ of total U.S. healthcare spending is estimated to be spent on medical liability. Medical liability includes items such as malpractice payments to patients, attorneys' fees and other legal expenses for both sides, and defensive medicine costs, which are the costs of medical services ordered primarily for the purpose of minimizing the physician's liability risk (Mello, Chandra, Gawande, \& Studdert, 2010).

\section{PROFESSIONAL RESPONSIBILITIES FOR NURSES}

Nurses are key to ensuring and improving quality of care and patient safety for patients and families, as well as for the organizations in which they work. Quality and Safety Competencies, developed as part of the Quality and Safety Education for Nurses (QSEN) initiative, that identify knowledge, skills, and attitudes that nursing students should achieve as part of their prelicensure programs and be able to exemplify in practice. They include the following:

- Patient-centered care

- Teamwork and collaboration

- Evidence-based practice (EBP)

- QI

- Safety

- Informatics (QSEN, 2014)

It is important to understand that the best way to exemplify these six competencies in practice is to apply each competency within the wider context of complex healthcare systems, which has not been the traditional approach for healthcare clinicians that have been educated to focus at the individual point of care (Dolansky \& Moore, 2013). In other words, clinicians tend to focus on the individual patient and their family, not necessarily how that patient and their family affect and are affected by the larger population and system of care. As such, to effectively apply each of the six competencies within the wider context of complex healthcare systems, nurses need to think about how performance can be measured, how the strengths of each team member can be maximized to improve care delivery to patients and improve their outcomes, and what can be done in the healthcare system to assure quality and safety and prevent harm from unintended consequences from errors. To take this one step further, in some circumstances, it is important to think about how nurses can accomplish QI and patient safety within organizations that may not truly have a culture of safety. It can be very difficult to improve quality and patient safety within an organization that does not have a culture of safety.

\section{CRITICAL THINKING 1.2}

In thinking about what you are learning in nursing school about patient safety and quality of care, go to http://qsen.org/competencies/pre-licensure-ksas/ and explore the specifics of each of the six QSEN competencies. 


\section{CRITICAL THINKING 1.2 (continued)}

1. What specific ways do you see the QSEN competencies being used in your nursing courses?

2. What specific ways do you see quality and safety being practiced in your clinical experiences?

\section{PREVENTING AND RESPONDING EFFECTIVELY TO ADVERSE EVENTS}

Strategies to reduce unwarranted variation and ensure predictable and favorable patient-care outcomes have proven successful in improving healthcare quality and patient safety. These strategies include developing checklists and other standardized tools, using best practices, and working in an organization with a culture of safety and communication when an error does occur. Checklists have been proven successful particularly in operating rooms and other areas where multiple tasks need to be accomplished consistently to ensure quality and safety. Checklists have demonstrated that they protect against failure, they establish a higher standard of baseline performance, and they are only an aid if they are done right to begin with (Gawande, 2011).

Standardized communication tools such as the SBAR (Situation, Background, Assessment, Recommendation) technique (www.ihi.org/resources/Pages/Tools/ SBARTechniqueforCommunicationASituationalBriefingModel.aspx), and using standardized order sets, protocols, and other best practices can be used by nurses and other members of the healthcare team to prevent errors, ensure quality care, and reduce variability in patient care and the potential for error.

It is important for nurses to work in organizations dedicated to a culture of safety and communication when an error does occur. Organizations that have a culture of safety are nonjudgmental, acknowledge the risk and error-prone nature associated with healthcare, and focus on improving healthcare systems and processes. In that quality and patient safety errors are often systems related and are not always attributable to individual negligence or misconduct, organizations that foster a culture of safety continuously strive to intercept errors before they happen, measure the quality of care processes and outcomes, and mitigate (or take action to minimize) harm involving patients. Organizations with a true culture of safety maintain an environment where nurses are not afraid to speak up and report errors or potential errors.

When something goes wrong and patients are harmed, it is difficult for clinicians, leadership, and patients. The first thing to remember is that when an adverse event occurs, it is important to respond in a timely manner, and as the Leapfrog Group recommends, do the following:

1. "Apologize to the patient and family

2. Waive all costs related to the event and follow-up care

3. Report the event to an external agency

4. Conduct a root-cause analysis of how and why the event occurred

5. Interview patients and families, who are willing and able, to gather evidence for the root cause analysis 
6. Inform the patient and family of the action(s) that the hospital will take to prevent future recurrences of similar events based on the findings from the root cause analysis

7. Have a protocol in place to provide support for caregivers involved in Never Events, and make that protocol known to all caregivers and affiliated clinicians

8. Perform an annual review to ensure compliance with each element of Leapfrog's Never Events Policy for each never event that occurred

9. Make a copy of this policy available to patients upon request" (Leapfrog Group, 2017)

One tool that health care organizations and providers can consider using to learn more about being successful after an adverse event occurs is the Communication and Optimal Resolution (CANDOR) kit. CANDOR is a communication and resolution process designed to open lines of communication between clinicians, patients, and their families after patient harm occurs. The free program (available at www.ahrq.gov/ professionals / quality-patient-safety / patient-safety-resources / resources / candor / introduction.html), includes eight training modules and also encourages clinicians to report near misses and errors to better inform patients (AHRQ, 2016).

\section{CRITICAL THINKING 1.3}

During your shift, you discover that the wrong medication was given to the wrong patient. Hospitals have policies and procedures that should be followed when a patient is given the wrong medication.

1. What are the policies and procedures at your clinical agency?

2. What do those policies state?

\section{WHY IS IT WRONG TO BLAME AND POINT FINGERS?}

When errors occur, we seem to traditionally blame the nurse as causing the error since many of the roles of nurses in patient care often put the nurse in direct contact with patients. In the past, we have even gone so far as to blame nursing leadership for "allowing" nurses to cause errors. By being in direct contact with patients, nurses are in a unique position to most likely be the only person in the room with the patient or the last person able to stop a chain of events that may result in an error. If a nurse is unable to stop an error from happening, the nurse is seen as literally at the sharp end of the arrow of blame. The term "sharp end" has been used to identify the important and significant direct contact role that nurses at the bedside, closest to clinical activities, play in recognizing the need for and potential impact of practice changes. Nurses may see the sharp end effects on patients and others first when the right care is not provided. Front line clinical nurses (as well as nurses in formal leadership positions) often assume leadership at the "sharp end" of care in direct contact with patients to assure safety and quality.

Nurses are qualified to offer invaluable insights and perspectives about what is preventing effective and efficient care as well as how the quality and safety of care can be improved based on their skills and experience. Other contributing factors, whether individual or health system related (e.g., such as the physician who may have ordered 
the wrong medication, or the design flaw in the infusion pump that malfunctioned), while maybe not in direct contact with the patient when the error occurred, also contribute to errors.

\section{CAN HEALTHCARE BE PERFECT?}

The quality and safety of care does not just spontaneously improve, and in many respects, it may not be possible to have error-free care that is of the highest quality at all times and in all places. Generally speaking, something needs to be done or someone needs to take action to either make improvements or ensure that a quality standard is maintained. A key goal of healthcare is to reduce unwarranted variation in healthcare safety and quality to ensure optimal patient outcomes. Yet even with the understanding that the quality of healthcare in the United States and throughout the world needs to improve, there is no consensus on how to best achieve consistent, high-quality care.

One of the challenges we have in improving healthcare is that nurses tend to be resilient-meaning that if something does not work well while they are providing care to a patient, they work around the "normal" way of doing things. These workarounds increase the opportunities for inconsistent care and inconsistent outcomes. Related to this, patients can also at times be resilient. For example, some patients can take the wrong medication at the wrong time and have no effects. Unfortunately, the resiliency of nurses coupled with the resiliency of patients does not guarantee the best possible outcomes nor does it ensure safe quality care.

Over the years, healthcare has become very complex. It involves multiple healthcare professionals and information from many sources. This complexity is closed linked with increased opportunities or increased risk for something going wrong and patients being harmed or the quality of care being compromised. Patients in hospitals and those that receive care from multiple healthcare providers at multiple sites of care are particularly vulnerable to safety and quality errors.

In an effort to ensure that safety is fundamental for every healthcare system, the IOM asserted that "Patients should not be harmed by the care that is intended to help them, nor should harm come to those who work in health care" (IOM, 1999).

IOM stated in its Crossing the Quality Chasm: A New Health System for the 21st Century (IOM, 2001) report that the healthcare system should focus on six aims (Table 1.4).

TABLE 1.4 SIX "STEEEP" AIMS OF THE HEALTHCARE SYSTEM

\begin{tabular}{|c|c|}
\hline Safe & $\begin{array}{l}\text { No one should ever be harmed by or as a consequence of receiving } \\
\text { healthcare services. }\end{array}$ \\
\hline Timely & Care should be obtained when needed with minimal delays. \\
\hline Effective & $\begin{array}{l}\text { The best available evidence should guide how healthcare is delivered } \\
\text { to achieve the best possible outcomes. }\end{array}$ \\
\hline Efficient & The quality of care should be maximized at the lowest, possible cost. \\
\hline Equitable & $\begin{array}{l}\text { Everyone should have equal quality of care even if patients may differ } \\
\text { in personal characteristics other than their clinical condition or } \\
\text { preferences for care. }\end{array}$ \\
\hline $\begin{array}{l}\text { Patient } \\
\text { centered }\end{array}$ & $\begin{array}{l}\text { A patient's culture, social context, and specific needs deserve } \\
\text { respect, and each patient should have an active role in making } \\
\text { decisions about their own care. }\end{array}$ \\
\hline
\end{tabular}

Source: Institute of Medicine (IOM). (2001). Crossing the Quality Chasm: A New Health System for the 21st Century. Retrieved from https://www.nap.edu/catalog/10027/crossing-the-quality-chasm-a-new-health-system-for-the 
The 2001 IOM report further noted that by focusing on these six aims, a transformation will begin to occur in the healthcare system. In another report, the IOM stated that healthcare systems needed to be redesigned to improve quality of care and patient safety, but to do so, organizations needed to meet these six challenges:

1. Redesign care processes

2. Make effective use of information technologies

3. Manage clinical knowledge and skills

4. Develop effective teams

5. Coordinate care across patient conditions, services, and settings over time

6. Incorporate performance and outcome measurements for improvement and accountability (IOM, 2001)

\section{INTERNATIONAL ADVANCES IN QUALITY AND SAFETY}

Researchers and healthcare providers throughout the world have been actively involved in improving patient safety and quality of care. Significant research and practice innovations have been developed primarily in the United Kingdom, Canada, Australia, and the United States. Research across the world on strategies to understand and improve healthcare quality and patient safety can be found throughout peer-reviewed healthcare journals.

Even though some may consider the United States as the leader in healthcare or in efforts to improve healthcare quality and patient safety, comparative studies by the Organization for Economic Cooperation and Development (OECD), the United Kingdom, and The Commonwealth Fund, among others, have consistently found that the United States does not have better healthcare outcomes than other industrialized nations, including countries in Europe, Australia, Canada, and New Zealand (The Commonwealth Fund, 2014; The Commonwealth Fund, 2015; The Health Foundation, 2015; OECD, 2017). Poor U.S. healthcare outcomes do not make sense when you consider the fact that year after year, the United States continues to spend more on healthcare (per capita), than any other country in the world (OECD, 2017). Higher spending appears to be largely driven by greater use and cost of medical technology (Table 1.5) and higher drug and healthcare prices, rather than by more frequent doctor visits or hospital admissions (Table 1.6). Despite spending more on healthcare, Americans have poor health outcomes, including shorter life expectancy, greater prevalence of chronic conditions, and higher infant mortality rates (The Commonwealth Fund, 2017; Table 1.7).

TABLE 1.5 SELECTED COSTS OF MEDICAL TECHNOLOGY

$\begin{array}{ll}\text { MRI machine } & \$ 1,541,788 \\
\text { OR table } & \$ 65,263 \\
\text { Electric bed } & \$ 15,981 \\
\text { Stretchers } & \$ 7,618 \\
\text { Implantable pacemaker } & \$ 3,820 \\
\text { Knee implant-femoral } & \$ 1,970 \\
\text { Drug-eluting stent } & \$ 1,189 \\
\text { Hip implant-acetabular shell } & \$ 1,073\end{array}$

Source: Modern Healthcare. Technology price index. Retrieved from http://www.modernhealthcare.com/section/technology-price-index 
TABLE 1.6 MEDICATION COSTS

\begin{tabular}{cll} 
& UNITED STATES & CANADA \\
\hline $100 \mathrm{mg}$ of sitagliptin (Januvia) & $\$ 382$ & $\$ 105.03$ \\
1 inhaler of Advair Diskus 250 & $\$ 386.97$ & $\$ 131.87$ \\
mcg/50 mcg & & \\
dimethyl fumarate (Tecfidera) & $\begin{array}{c}60 \text {-capsule package of } 120 \\
\text { mg costs } \$ 6,805.76 \text { or }\end{array}$ & $\begin{array}{c}42 \text { capsule supply } \\
\text { of } 120 \mathrm{mg} \text { costs }\end{array}$ \\
& $\begin{array}{l}\$ 113 \text { per capsule } \\
\end{array}$ & $\begin{array}{l}\$ 1,177.80, \text { or } \\
\text { capsule }\end{array}$ \\
\hline
\end{tabular}

Source: The Motley Fool. (2017). 5 drugs that are way cheaper in Canada. Retrieved from https://www.fool.com/ investing/2017/01/21/5-drugs-that-are-way-cheaper-in-canada.aspx

While organizations focused on improving the quality and safety of care have been previously mentioned in this chapter, there are similar organization outside the United States and even organizations within the United States that are focusing on either country-specific goals or global initiatives. For example, the European Medicines Agency and Health Canada have similar functions as the FDA in the United States The U.S.-based Joint Commission, has an international component that has established the International Patient Safety Goals that are used worldwide, including:

1. "Identify patients correctly

2. Improve effective communication

3. Improve the safety of high-alert medications

4. Ensure safe surgery

5. Reduce the risk of healthcare-associated infections

6. Reduce the risk of patient harm resulting from falls" (Joint Commission International [JCI], 2017)

Each of these international goals can be related to the U.S.-based Joint Commissions patient safety goals. The World Health Organization (WHO) also continues to lead worldwide efforts to improve patient safety (see www.who.int/patientsafety/en as an example). And since 1998, the Australian Patient Safety Foundation has also led key initiatives to improve patient safety (see apsf.net.au).

As these and other countries became involved in focusing on improving quality and safety of healthcare, inconsistency continued in how patient safety terms were used across nations, which hampered global advances to improve patient safety. The World Alliance for Patient Safety, a part of the WHO, developed the International Patient Safety Classification framework to facilitate a common understanding and use of definitions and preferred terms for patient safety (WHO, 2009; see www.who.int/ patientsafety/taxonomy/icps_statement_of_purpose.pdf). Also, there has been inconsistency in how quality and safety of care is measured. The OECD developed a set of indicators for comparing the quality of health across OECD member countries through its Health Care Quality Indicator Project (see www.oecd.org/els/health-systems / health-care-quality-indicators.htm). 


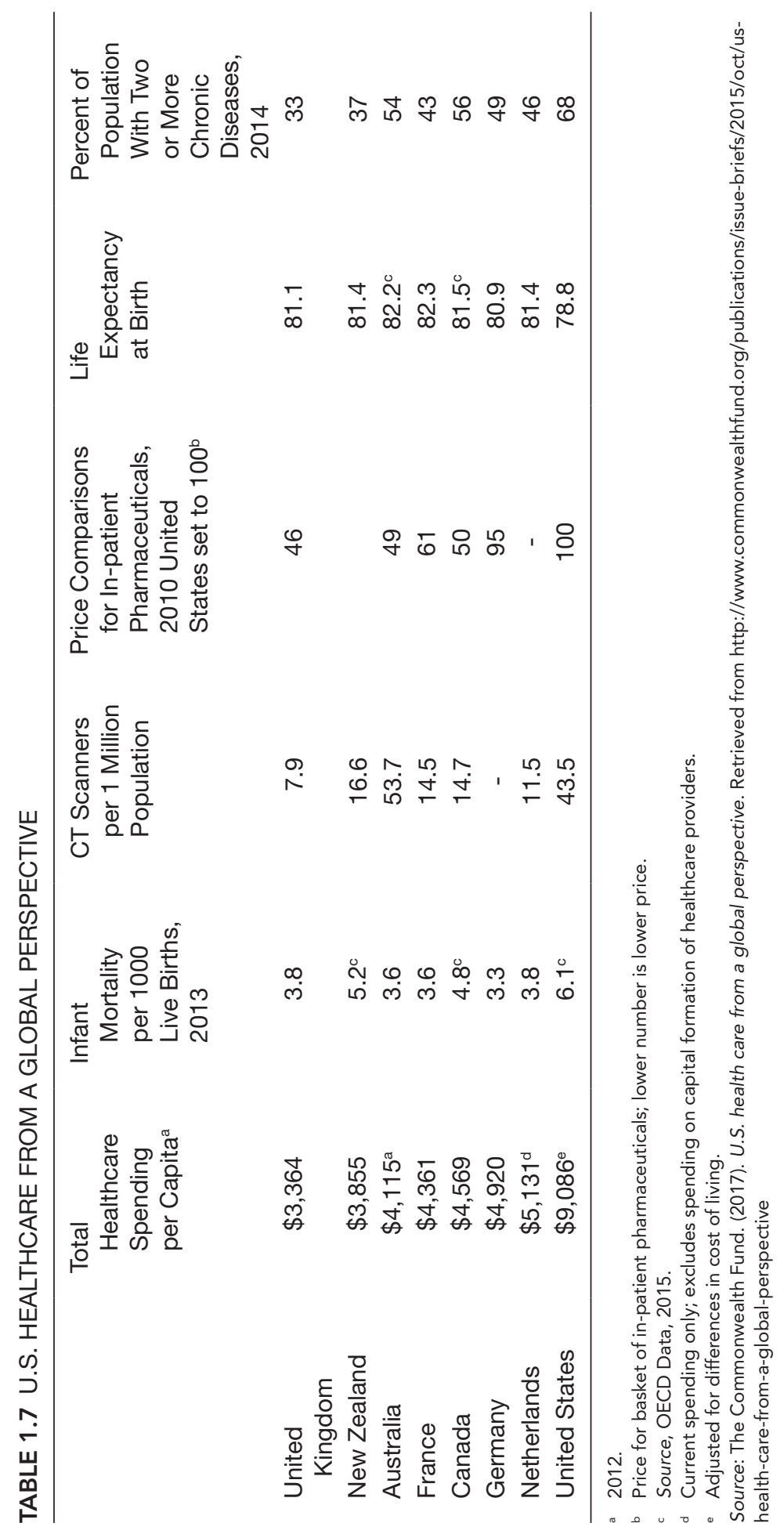




\section{EVIDENCE FROM THE LITERATURE}

\section{Citation}

Marsa, L. (2017, September). Take charge of your health care: Surgeries and side effects. (p. 20).

\section{Discussion}

These are among the most common surgeries for Americans over 50 and the most common complications. In $2 \%$ to $4 \%$ of all cases, complications happen, and the patient needs to be readmitted to the hospital within 30 days.

\begin{tabular}{lll} 
SURGERY & COMPLICATION & OCCURRENCE \\
Cataract removal & Posterior capsule opacity & $20 \%$ \\
Pacemaker implant & Hematoma & $2.2 \%$ in patients over 70 \\
Colectomy & Infection & $12.4 \%$ \\
Coronary artery bypass & Atrial Fibrillation & $24 \%$ \\
Hip replacement & Dislocation & $2 \%$ \\
Knee replacement & Blood Clot & $1 \%$ \\
Prostate removal & Bleeding & $5.3 \%$ \\
Inguinal Hernia & Infection & $0.3 \%$ Open surgery \\
& & $0.2 \%$ Laparoscopic surgery \\
Cholecystectomy & Infection & $7.6 \%$ Open surgery \\
Appendectomy & & $1 \%$ Laparoscopic surgery \\
& Infection & $4.3 \%$ Open surgery \\
& & $1.9 \%$ Laparoscopic surgery \\
\hline
\end{tabular}

Implications for Nursing: Nurses must be aware of the higher incidence of complications in patients over 50 and, when possible, implement nursing care strategies to prevent complications.

\section{WHAT IS THE COST OF ACHIEVING QUALITY AND SAFETY}

From a systems perspective, the cost of providing safety and quality care comes at a cost (Table 1.8). Across types of healthcare organizations, there are many categories of costs, primarily including the costs of healthcare salaries (Table 1.9), costs associated with the technology used to provide healthcare services, and the cost of the physical space where healthcare is delivered. Hospitals also have significant costs when it comes to ensuring quality of care and patient safety. While some of these costs can be seen as high, the cost of poor quality of care far exceeds these amounts. The majority of hospitals in the United States (American Hospital Association [AHA], 2017) are required by the CMS to meet TJC accreditation requirements to be reimbursed for care received by Medicare and Medicaid beneficiaries, who represent the majority of hospitalized patients. There are over 4,000 hospitals and approximately $77 \%$ of them are currently accredited by TJC (2017). The accreditation process, which includes an expensive onsite survey, recurs every 3 years (JCI, 2017). 
TABLE 1.8 SELECTED COSTS OF ACHIEVING QUALITY OF CARE AND PATIENT SAFETY

\begin{tabular}{|c|c|c|c|}
\hline ORGANIZATION & REQUIREMENT & WHAT IS INVOLVED & $\begin{array}{l}\text { AVERAGE ANNUAL } \\
\text { COST }\end{array}$ \\
\hline Hospital & $\begin{array}{l}\text { Joint } \\
\text { Commission } \\
\text { Accreditation }\end{array}$ & $\begin{array}{l}\text { - Meeting each of the } \\
\text { standards } \\
\text { - Planning for the survey } \\
\text { - Staff time in record } \\
\text { keeping and treatment } \\
\text { planning } \\
\text { - Conducting a mock } \\
\text { - } \text { survey } \\
\text { - Actual survey }\end{array}$ & $\begin{array}{l}\text { Approximately } \\
0.03 \% \text { to } 1 \% \\
\text { of a hospital's } \\
\text { operating budget. } \\
\text { Annual fees are } \\
\text { based on type of } \\
\text { hospital, volume, } \\
\text { and types of } \\
\text { services provided } \\
\text { (TJC, 2017c) }\end{array}$ \\
\hline $\begin{array}{l}\text { Home care } \\
\text { agency }\end{array}$ & $\begin{array}{l}\text { Joint } \\
\text { Commission } \\
\text { Accreditation }\end{array}$ & $\begin{array}{l}\text { - Meeting each of the } \\
\text { standards } \\
\text { - Planning for the survey } \\
\text { - Staff time in record keeping } \\
\text { and treatment planning } \\
\text { - Conducting a mock survey } \\
\text { - Actual survey }\end{array}$ & $\begin{array}{l}\text { Average of } \$ 1,500 \\
\text { for single-service } \\
\text { home care } \\
\text { providers, and } \\
\text { onsite survey fee } \\
\text { of } \$ 3,240 \text { (TJC, } \\
2015 \text { ) }\end{array}$ \\
\hline $\begin{array}{l}\text { Healthcare } \\
\text { organization }\end{array}$ & Director of QI & $\begin{array}{l}\text { Lead and direct process } \\
\text { improvement activities } \\
\text { to provide efficient and } \\
\text { effective care }\end{array}$ & $\begin{array}{l}\text { Average salary }= \\
\$ 109,293 \text { (range } \\
\$ 95,713-\$ 127,272) \\
\text { (Salary.com) }\end{array}$ \\
\hline $\begin{array}{l}\text { Healthcare } \\
\text { organization }\end{array}$ & $\begin{array}{l}\text { Nursing } \\
\text { informatics } \\
\text { specialist }\end{array}$ & $\begin{array}{l}\text { Manage information and } \\
\text { communications (including } \\
\text { documentation) for nursing }\end{array}$ & $\begin{array}{l}\text { Average salary = } \\
\text { over } \$ 100,000 \\
\text { (HIMSS, 2017) }\end{array}$ \\
\hline Hospital & $\begin{array}{l}\text { Magnet }^{\circledR} \\
\text { Accreditation }\end{array}$ & $\begin{array}{l}\text { - Performing a gap analysis } \\
\text { to identify problems } \\
\text { - Meeting each of the } \\
\text { Magnet }{ }^{\circledR} \text { requirements } \\
\text { - Preparing and submitting } \\
\text { an application and required } \\
\text { documentation } \\
\text { - Actual site visit survey }\end{array}$ & $\begin{array}{l}\text { Average annual } \\
\text { cost of } \$ 500,000 \\
\text { (total average } \\
\text { investment of } \\
\$ 2,125,000 \\
\text { over several } \\
\text { years) (Robert } \\
\text { Wood Johnson } \\
\text { Foundation } \\
\text { [RWJF], 2014) }\end{array}$ \\
\hline $\begin{array}{l}\text { Healthcare } \\
\text { organization }\end{array}$ & $\begin{array}{r}\text { Baldrige } \\
\text { Award }\end{array}$ & $\begin{array}{l}\text { - Meeting each of the } \\
\text { criteria } \\
\text { - Preparing and submitting } \\
\text { an application and } \\
\text { required documentation }\end{array}$ & $\begin{array}{l}\text { Eligibility certification } \\
=\$ 400 \text { (initial cost) } \\
\text { then the } \\
\text { application fee } \\
=\$ 10,560 \\
\text { to } \$ 19,800, \\
\text { supplemental } \\
\text { section }=\$ 1,100 \\
\text { to } \$ 2,200, \text { and site } \\
\text { visit }=\$ 33,000 \\
\text { to } \$ 66,000 \\
\text { (National Institute } \\
\text { of Standards and } \\
\text { Technology [NIST], } \\
\text { 2016) }\end{array}$ \\
\hline
\end{tabular}


TABLE 1.9 SELECTED HEALTHCARE SALARIES

\begin{tabular}{|c|c|c|}
\hline ROLE & SALARY & SOURCE \\
\hline $\begin{array}{l}\text { CEO, Merck } \\
\text { Pharmaceuticals }\end{array}$ & $\$ 24.2$ million & $\begin{array}{l}\text { www.usatoday.com/story/money/ } \\
\text { markets/2016/08/26/drug- } \\
\text { money-pharma-ceos-paid-71- } \\
\text { more/89369152/, Retrieved September } \\
\text { 10, } 2017\end{array}$ \\
\hline Anesthesiologist & $\begin{array}{l}\text { Mean annual } \\
\text { wage } \$ 269,600\end{array}$ & $\begin{array}{l}\text { www.bls.gov/oes/current/oes291061. } \\
\text { htm, Retrieved September 10, } 2017\end{array}$ \\
\hline General practitioner & $\begin{array}{l}\text { Mean annual wage } \\
\$ 200,810\end{array}$ & $\begin{array}{l}\text { www.bls.gov/oes/current/oes291062. } \\
\text { htm, Retrieved September 10, } 2017\end{array}$ \\
\hline Nurse practitioner & $\begin{array}{l}\text { Mean annual } \\
\text { wage } \$ 104,610\end{array}$ & $\begin{array}{l}\text { www.bls.gov/oes/current/oes291171. } \\
\text { htm, Retrieved September 10, } 2017\end{array}$ \\
\hline Pharmacist & $\begin{array}{l}\text { Median annual } \\
\text { wage } \$ 122,230\end{array}$ & $\begin{array}{l}\text { www.bls.gov/ooh/healthcare/ } \\
\text { pharmacists.htm, Retrieved September } \\
\text { 10, } 2017 .\end{array}$ \\
\hline Dietitian & $\begin{array}{l}\text { Median annual } \\
\text { wage } \$ 58,920\end{array}$ & $\begin{array}{l}\text { www.bls.gov/ooh/healthcare/dietitians- } \\
\text { and-nutritionists.htm, Retrieved } \\
\text { September 10, } 2017 \text {. }\end{array}$ \\
\hline Registered nurse & $\begin{array}{l}\text { Median annual } \\
\text { wage, } \$ 68,450\end{array}$ & $\begin{array}{l}\text { www.bls.gov/ooh/healthcare/registered- } \\
\text { nurses.htm, Retrieved September 10, } \\
2017\end{array}$ \\
\hline $\begin{array}{l}\text { Licensed practical } \\
\text { nurse }\end{array}$ & $\begin{array}{l}\text { Median annual } \\
\text { wage } \$ 44,090\end{array}$ & $\begin{array}{l}\text { www.bls.gov/ooh/healthcare/licensed- } \\
\text { practical-and-licensed-vocational- } \\
\text { nurses.htm, Retrieved September 10, } \\
2017 \text {. }\end{array}$ \\
\hline Nursing assistant & $\begin{array}{l}\text { Median annual } \\
\text { wage } \$ 26,590\end{array}$ & $\begin{array}{l}\text { www.bls.gov/ooh/healthcare/nursing- } \\
\text { assistants.htm, Retrieved September } \\
\text { 10, } 2017 .\end{array}$ \\
\hline
\end{tabular}

There are also costs and savings for outpatient organizations when it comes to improving quality of care. For example, improving a patient's glucose management would increase the average cost per individual with diabetes by $\$ 327$ per year, but would save between $\$ 555$ to $\$ 1,021$ annually (Nuckols et al., 2011).

Preventing hospital-acquired conditions (HACs), such as adverse drug events, falls, pressure ulcers and healthcare associated infections, can avert death. For example, about $44 \%$ of HACs are considered preventable. Recent decreases in the number of HACs has resulted in billions of dollars of savings for national healthcare expenses (AHRQ, 2015).

\section{RECOGNIZING HOSPITAL EXCELLENCE}

The most recognized award for excellence within a hospital is the Baldrige Award. The Baldrige Health Care Criteria for Performance Excellence have been used by many healthcare organizations to improve quality. Recipients of the Baldrige Award are selected based on the following Criteria for Performance Excellence:

1. Leadership: How upper management leads the organization and how the organization leads within the community.

2. Strategy: How the organization establishes and plans to implement strategic directions. 
3. Customers: How the organization builds and maintains strong, lasting relationships with customers.

4. Measurement, analysis, and knowledge management: How the organization uses data to support key processes and manage performance.

5. Workforce: How the organization empowers and involves its workforce.

6. Operations: How the organization designs, manages, and improves key processes.

7. Results: How the organization performs in terms of customer satisfaction, finances, human resources, supplier and partner performance, operations, governance and social responsibility, and how the organization compares to its competitors" (ASQ, 2017).

The Criteria for Performance Excellence is based on a set of core values. Award recipient organizations are considered to have a role-model organizational management system that continuously makes improvements in delivering products and/or services, demonstrates efficient and effective operations, and provides a way of engaging and responding to customers and other stakeholders.

\section{RECOGNIZING NURSING EXCELLENCE}

The American Nurses Credentialing Center's (ANCC, 2017) Magnet Recognition Program awards healthcare organizations that have achieved superior performance and is often referred to as the ultimate credential for high-quality nursing. The Magnet Recognition Program evaluates sources of evidence that create the foundational infrastructure for excellence, while its focus on results fosters a culture of quality and innovation. To achieve Magnet Recognition, organizations participate in a rigorous review process where organizations must demonstrate support of professional clinical practice, promote excellence in the delivery of nursing services to patients, and have processes to promote best nursing practices (ANCC, 2017).

Similar to the Magnet Recognition Program, but not as expensive and not requiring as extensive a process, is the Pathway to Excellence Program. To be nationally recognized and designated for the Pathway to Excellence Program, a healthcare organization must meet specific practice standards, including:

1. Shared decision making

2. Leadership

3. Safety

4. Quality

5. Well-being

6. Professional development (ANCC, 2017).

Organizations earn the award by demonstrating that their practices and policies help create a safe, positive work environment for nurses and high-quality, safe care for patients.

There are also numerous opportunities for individual credentialing, where licensed nurses complete a specific number of education hours and/or hours of experience and take a test to demonstrate mastery of a body of knowledge and acquired skills in a particular specialty (McHugh et al., 2014). The ANCC, among many other organizations, offers numerous certification for the various types of nursing care (see http:/ /www. nursecredentialing.org/Certification). 


\section{NURSE LEADER AND MANAGER}

RADM Jessie M. Scott, DSc, RN, FAAN, was Assistant Surgeon General in the U.S. Public Health Service and led the Division of Nursing for 15 years. She was instrumental in the passage and implementation of the Nurse Training Act. Her career led her to address nursing shortages from Arkansas to Connecticut and later to work with nursing education programs in India, Egypt, Liberia, and Kenya. Read more about her at www.nursingworld.org/halloffame

\section{ROLE OF NURSE LEADERS IN ENSURING QUALITY AND SAFETY}

In 2010, the IOM released the report, The Future of Nursing: Leading Change, Advancing Health (IOM, 2010). The key message of the report was for nurses to take a greater leadership role across care settings in the increasingly complex U.S. healthcare system. As the population ages and becomes increasingly diverse and to effectively respond to the changes and complexity of healthcare, the report examines how the roles, responsibilities and education

TABLE 1.10 IOM RECOMMENDATIONS FOR THE FUTURE OF NURSING, 2010, AND 2015

\section{IOM RECOMMENDATIONS-2010}

- Remove scope of practice barriers

- Implement nurse residency programs

- Expand opportunities for nurses to lead and diffuse collaborative improvement efforts

- Double the number of nurse with a doctorate by 2020

- Build an infrastructure for collection and analysis of interprofessional healthcare workforce data

- Increase the proportion of nurses with a baccalaureate degree to $80 \%$ by 2010

- Ensure that nurses engage in lifelong learning

- Prepare and enable nurses to lead change to advance health

\section{IOM RECOMMENDATIONS-2015}

- Build common ground with other health professions groups around scope of practice and other issues in policy and practice

- Create and fund transition-to-practice residency programs

- Expand efforts and opportunities for interprofessional collaboration and leadership development for nurses

- Make diversity in the nursing workforce a priority.

- Promote nurses' pursuit of doctoral degrees

- Continue pathways toward increasing the percentage of nurses with a baccalaureate degree

- Promote nurses' interprofessional and lifelong learning

- Promote the involvement of nurses in the redesign of care delivery and payment systems

- Improve workforce data collection

- Communicate with a wider and more diverse audience to gain broad support for campaign objectives

Source: Institute of Medicine (IOM). (2010). The future of nursing: Leading, changing, advancing health. Retrieved from http://nationalacademies.org/HMD/Reports/2010/The-Future-of-Nursing-Leading-Change-Advancing-Health.aspx 
of nursing should change to improve healthcare for everyone. In that nurses represent the largest segment of the healthcare workforce, the IOM recommended that nursing:

1. Be able to practice "to the full extent of their education and training

2. Improve nursing education

3. Assume leadership positions and serve as full partners in healthcare redesign and improvement efforts

4. Improve data collection for workforce planning and policy making" (IOM, 2010)

A few years later, the IOM released a report on the progress achieved on the IOM 2010 report recommendations (see Table 1.10), focusing on the areas of removing barriers to practice and care; transforming education; collaborating and leading; promoting diversity; and improving data. In this report, the IOM committee concluded that "no single profession, working alone, can meet the complex needs of patients and communities. Nurses should continue to develop skills and competencies in leadership and innovation and collaborate with other professionals in healthcare delivery and health system redesign. To continue progress on the implementation of The Future of Nursing recommendations and to effect change in an evolving healthcare landscape, the nursing community must build and strengthen coalitions with stakeholders both within and outside of nursing" (IOM, 2015).
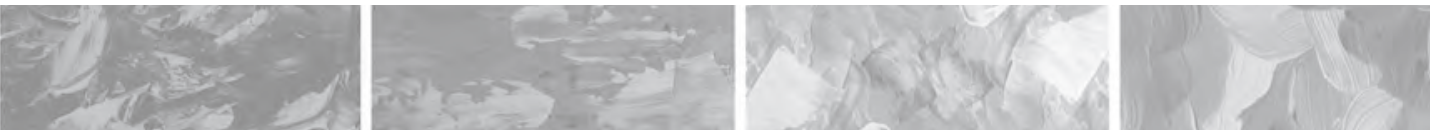

\section{KEY CONCEPTS}

1. Healthcare quality is defined as "the degree to which healthcare services for individuals and populations increase the likelihood of desired health outcomes and are consistent with current professional knowledge" (IOM, 2001).

2. Several organizations have significant roles in influencing the quality of care and patient safety; , for example, The ISMP, The NAM, The NQF, IHI, TJC, The Leapfrog Group, HFMA.

3. Data from CMS Hospital Compare provide information on the quality of care provided to patients in hospitals and includes information about patients' experiences (HCAHPS), timely \& effective care, complications, readmissions and deaths, use of medical imaging, payment and value of care.

4. There are several examples of quality care and patient safety measures that are used primarily in healthcare organizations, such as hospitals, nursing homes, and outpatient clinics; for example, the CMS Core Measures, AHRQ Quality Indicators, AHRQ Patient Safety Indicators, NQF and ANA Nurse Sensitive Indicators, and the NCQA HEDIS Measures.

5. Unwanted variation is variation in the use of medical care that cannot be explained on the basis of illness, medical evidence, or patient preferences.

6. Transparency is considered to include reporting not only the real cost of care, but also clearly reporting information about performance failures as well as successes (Austin et al., 2016).

7. It has been estimated that, while hospitalized, about one in four patients experience one or more adverse events that result in a longer hospital stay, permanent harm, the need for a life-sustaining intervention, or death. Of these adverse events that resulted in injury, almost half were preventable (OIG, 2010). 
8. Nurses are key to ensuring and improving quality of care and safety for patients and families, as well as for the organizations in which they work.

9. Strategies to reduce unwarranted variation and ensure predictable and favorable patient-care outcomes have proven successful in improving healthcare quality and patient safety; for example, developing checklists and other standardized tools, using best practices, working in an organization with a culture of safety, and communication when an error does occur.

10. Standardized communication tools such as the SBAR technique and using standardized order sets, protocols, and other best practices can be used by nurses and other members of the healthcare team to prevent errors, ensure quality care, and reduce variability in patient care and the potential for error.

11. The term "sharp end" has been used to identify the important and significant direct contact role that nurses at the bedside, closest to clinical activities, play in recognizing the need for and potential impact of practice changes. Nurses may see the sharp end effects on patients and others first when the right care is not provided. Front line clinical nurses (as well as nurses in formal leadership positions) often assume leadership at the "sharp end" of care in direct contact with patients to ensure safety and quality.

12. Workarounds may occur when something doesn't work well while nurses are providing care to a patient and they work around the "normal" way of doing things. These workarounds increase the opportunities for inconsistent care and inconsistent outcomes.

13. Even though some may consider the United States as the leader in healthcare or in efforts to improve healthcare quality and patient safety, comparative studies by the OECD, the United Kingdom, and The Commonwealth Fund, among others, have consistently found that the United States does not have better healthcare outcomes than other industrialized nations, including countries in Europe, Australia, Canada, and New Zealand (The Commonwealth Fund, 2014; The Health Foundation, 2015; OECD, 2017).

14. Poor U.S. healthcare outcomes do not make sense when you consider the fact that year after year, the United States continues to spend more on healthcare (per capita), than any other country in the world (OECD, 2017).

15. Higher U.S. spending appears to be largely driven by greater use and cost of medical technology and higher drug and healthcare prices, rather than by more frequent doctor visits or hospital admissions.

16. Despite spending more on healthcare, Americans have poor health outcomes, including shorter life expectancy, greater prevalence of chronic conditions, and higher infant mortality rates (The Commonwealth Fund, 2017).

17. The U.S.-based Joint Commission has an international component that has established the International Patient Safety Goals that are used worldwide.

18. The majority of hospitals in the United States (AHA, 2017) are required by the CMS to meet TJC accreditation requirements to be reimbursed for care received by Medicare and Medicaid beneficiaries, who represent the majority of hospitalized patients.

19. There are over 4,000 hospitals and approximately $77 \%$ of them are currently accredited by TJC (TJC, 2017).

20. The CEO of Merck Pharmaceuticals has an annual salary of $\$ 24.2$ million.

21. The Baldrige Health Care Criteria for Performance Excellence has been used by many healthcare organizations to improve quality.

22. ANCC Magnet Recognition Program awards healthcare organizations that have achieved superior performance and is often referred to as the ultimate credential for high-quality nursing. 


\section{KEY TERMS}

Adverse event

Errors

Healthcare quality

High-quality care
Sentinel events

Sharp end

Transparency

\section{REVIEW QUESTIONS}

1. A group of emergency department nurses are asked to develop an action plan to improve the time before patients who present with chest pain receive an ECG. Which of the following would not be helpful when working on a QI effort like this?
A. Identify an interprofessional group of individuals to help review current performance.
B. Compare current hospital emergency department data results to benchmark comparison information reported on a national website.
C. Post current hospital performance data results openly to staff in the nursing lounge.
D. Identify whose fault it is that results are not very good.

2. As a staff nurse you are interested in making QIs in the overall care of patients with heart failure. Where would be most helpful to look for data and information to help you get started with these improvements?
A. Explore the IHI website (www.IHI.org), which includes white papers, evidence-based protocols, blogs, and improvement stories that can be applied to patients with heart failure. and statistics related to cancer care, resources, and latest research developments.
B. Review the National Cancer Institute's website, which includes facts
C. Review drug companies' websites to see if there are any new medications available to treat heart failure.
D. Google "heart failure" to see if you can get access to the latest treatment options for this patient population.

3. An 87-year-old patient was admitted to an acute care hospital. The patient was in a severe automobile vehicle accident. He is unconscious in intensive care and on a ventilator. On Day 3 of the patient's hospitalization, the patient experiences a cardiac arrest and a code blue is called. The code blue lasts for an hour. The patient's heart rhythm is restored. When the family is notified of the event, the wife is very upset. She states she had provided the hospital with the patient's advance directive, which clearly stated the patient should not be resuscitated. You are the nurse talking to the wife. What do you do?
A. Apologize, but state that the patient was a full code, which means he must be resuscitated. physician and your nurse manager that the problem occurred. The risk management department will probably review this case.
B. Apologize, and assure the wife that you will be contacting the attending 
C. Notify the wife that the advance directive is not legal or binding and that the wife needed to tell them specifically that the patient did not want to be resuscitated.

D. Tell the wife to try to focus on the positive, that her 87 -year-old husband is still alive.

4. A patient asks a nurse what it means to have a hospital accredited by TJC. Which one of the following is not a Joint Commission quality compliance requirement?
A. Billing models
B. Core measures
C. Safe practice measures
D. Process improvement efforts

5. A patient read that hospitals are not getting reimbursed by the CMS for certain never events and asks a nurse to explain. Which one of the following is an example of a never event?
A. Absence of a hospice unit within the hospital
B. Emergency department admissions of over 1,000 per month
C. Nursing stations located at the end of the hall versus in the middle of the patient-care unit
D. Stage IV hospital-acquired pressure ulcer

6. What is a common cause of errors within healthcare settings?
A. Uncaring professionals
B. Incompetent caregivers
C. Communication problems between caregivers
D. Phones not connecting to the nurse's station

7. QSEN has developed multiple quality and safety competencies to guide nursing practice. Identify which of these are considered a part of the six key competencies.

A. QI, teamwork and collaboration, and EBP

B. Fact finding, mission statements, and strategic planning

C. Stakeholder feedback, budget reconciliation, and strategic planning

D. Financial reporting, wait time measurements, and time delays in getting treatments

8. You are the nurse caring for a patient who was recently told he has heart failure. The patient will be relocating next week to a different state. The patient has a primary care provider in his new state and intends to follow up as instructed upon discharge. However, he would like to identify an acute care hospital in his new state that is adept in caring for heart failure patients, in the event that he needs to be admitted. The patient asks for your recommendation. All of the suggestions below may give him good information. What would be your best suggestion to the patient so that he may make a well-informed, objective decision?

A. Tell the patient that hospitals publicly report their quality data associated with caring for heart failure patients on a website and instruct him where he can retrieve this information. 

B. Tell him to ask members in the community or family and friends where they have had good experiences.
C. Tell him to ask his primary care provider for a recommendation.
D. Tell him to visit the websites of hospitals in the community where he is moving.

9. You are an administrator working in an urban health system. You have been charged to lead the efforts of redesigning the patient-care delivery model. This model is intended to best represent patient expectations. As such, in developing the model, you recognize the importance of taking into account the patient's quality concerns. Which answer best represents the top patient quality concerns as described by the HFMA Value Project (2011)?
A. Access: Make care available and affordable. Safety: Do not hurt me. Outcomes: Make me better. Respect: Respect me as a person, not a case.
B. Access: Make care available and affordable. Safety: Do not hurt me. Quality: Provide high-quality care. Respect: Respect me as a person, not a case.
C. Safety: Do not hurt me. Outcomes: Make me better. Value: Deliver care at a reasonable price. Inclusion: Include my loved ones in any care plans.
D. Safety: Do not hurt me. Quality: Provide high-quality care. Value: Deliver care at a reasonable price. Respect: Respect me as a person, not a case.

\section{QSEN ACTIVITIES}

1. Go to the QSEN website (www.qsen.org) and search for Quality. Click on Quality Improvement (www.homehealthquality.org/Education/Best-Practices. aspx). Work on Cardiovascular Health Part 1 (www.homehealthquality.org/ Education/Best-Practices/BPIPs / Cardiovascular-Health-Part-1-BPIP.aspx). Can this information help improve patient safety?

2. Go to the QSEN website (www.qsen.org) and search for Quality. Click on Quality Improvement (www.homehealthquality.org/Education/Best-Practices.aspx). Work on Cardiovascular Health Part 2. Can this information help improve patient safety?

\section{REVIEW ACTIVITIES}

1. Go to the QSEN Institute website, qsen.org. Click on Competencies, Pre-Licensure. Also, click on Teaching Strategies. What did you find at these sites that apply to you as a student?

2. What patient safety challenges do you see in hospitals or in outpatient care sites?

3. Read through the summary of recommendations for two reports in the Quality Chasm series (go to www.nap.edu/catalog/21895/quality-chasm-series-healthcare-quality-reports), and look at the list of recommendations. Of these recommendations, what surprised you?

\section{CRITICAL DISCUSSION POINTS}

1. Are all adverse events inevitable?

2. How is the FDA involved in improving patient safety? 
3. Do sentinel events have to be reported to TJC?

4. Are there similarities in the measures of patient safety and the measures of quality of care (Table 1.3)?

5. Should only events that harm patients be reported to external quality and safety organizations?

6. Are patients safer if they stay in the hospital longer?

7. Name three of the QSEN competencies.

8. Does blaming a nurse for an error improve patient safety?

9. Name the six aims of the healthcare system from the IOM Crossing the Quality Chasm 2001 report.

10. Is improving quality and patient safety expensive?

\section{EXPLORING THE WEB}

1. AHRQ-www.ahrq.gov

2. ANCC-www.nurscredentialing.org

3. Baldrige Foundation-www.baldrigefoundation.org

4. CMS-www.cms.gov

5. FDA-www.fda.gov

6. IHI-www.ihi.org

7. NQF-www.qualityforum.org

8. QSEN Institute-qsen.org

9. Quality Chasm Series-www.nap.edu/catalog/21895/quality-chasm-series-healthcare-quality-reports?gclid=EAIaIQobChMIjIeh35-31QIVBoNpCh2y0ASvEAAYASA AEgIhY_D_BwE

10. TJC-www.jointcommission.org

11. U.S. News and World Report ratings of hospitals-health.usnews.com/besthospitals/rankings

\section{EVIDENCE FROM THE LITERATURE}

Citation: The Economist. (2018). Land of the free-for-all: America is a health-care outlier in the developed world. Retrieved from www.economist.com/news/ special-report/21740871-only-large-rich-country-without-universal-healthcare-america-health-care-outlier

\section{DISCUSSION}

America has some of the best hospitals in the world but it is also the only large rich country without universal healthcare coverage. About half of Americans have their health insurance provided by their employers. Healthcare costs can be financially ruinous for others. In 2016, America spent $\$ 10,348$ per person on healthcare, roughly twice as much as the average for comparably rich countries. On average, both hospital cost and drug prices can be $60 \%$ higher than in Europe. The American Affordable Care Act expanded the health insurance system and cut the number of uninsured people from 44 million to 28 million but still left a gap among people not poor enough to qualify for Medicaid but not rich enough to buy private insurance. 
In the United States, prices for the same service can vary enormously. Having your appendix removed, for example, can cost anywhere from $\$ 1,500$ to $\$ 183,000$ depending on the insurer. Add to this the fact that nine of the 10 best-paid occupations in the United States involve medicine and we see that doctors have little incentive to change the system.

Implication for practice: Nurses must participate in the discussion about the improvement of healthcare.

\section{REFERENCES}

Agency for Healthcare Research and Quality (AHRQ). (2011). Health care quality still improving slowly, but disparities and gaps in access to care persist, according to new AHRQ reports. Retrieved from https://archive.ahrq.gov/news/newsletters/patient-safety/66.html

Agency for Healthcare Research and Quality (AHRQ). (2015). Efforts to improve patient safety result in 1.3 million fewer patient harms. Rockville, MD: Agency for Healthcare Research and Quality. Retrieved from http:/ / www.ahrq.gov/professionals/quality-patient-safety/pfp/ interimhacrate2013.html

Agency for Healthcare Research and Quality (AHRQ). (2016). Communication and optimal resolution toolkit (CANDOR). Retrieved from https://www.ahrq.gov/professionals/qualitypatient-safety/patient-safety-resources/resources/candor/introduction.html

Agency for Healthcare Research and Quality (AHRQ). (2017a). Patient safety indicators overview. Retrieved from https://www.qualityindicators.ahrq.gov/modules/psi_resources.aspx

Agency for Healthcare Research and Quality (AHRQ). (2017b). Inpatient quality indicators. Retrieved from https://www.qualityindicators.ahrq.gov/modules/iqi_resources.aspx

Agency for Healthcare Research and Quality (AHRQ). (2017c). Patient safety primer. Culture of safety. Retrieved from https://psnet.ahrq.gov/primers/primer/5/safety-culture

American College of Physicians (ACP). (2010). Healthcare transparency-Focus on price and clinical performance information. Retrieved from https://www.acponline.org/system/files/documents/advocacy/current_policy_papers/assets/transparency.pdf

American Hospital Association (AHA). (2017). AHA hospital statistics: A comprehensive reference for analysis and comparison of hospital trends. Retrieved from http:/ / www.aha.org/research/ rc/stat-studies/fast-facts.shtml

American Nurses Association (ANA). (2010). Nursing-sensitive indicators. Retrieved from http:/ / www.nursingworld.org

American Nurses Credentialing Center (ANCC). (2017). Practice standards. Retrieved from https://www.nursingworld.org/organizational-programs/pathway/

Aspden, P., Corrigan, J., Wolcott, J., \& Erickson, S. M. (Eds.) (2004). Patient safety: Achieving a new standard for care. Washington, DC: National Academies Press.

ASQ. (2017). Malcolm Baldrige national quality award (MBNQA). Retrieved from http:/ /asq.org/ learn-about-quality/malcolm-baldrige-award/overview/overview.html

Austin, J. M., McGlynn, E.A., \& Pronovost, P.J. (2016). Fostering transparency in outcomes, quality, safety, and costs. JAMA, 316(16), 1661-1662.

Berwick, D. (2009, August 28). In Bill Moyers" journal. Retrieved from http://www.pbs.org/ moyers/journal/08282009/transcript1.html

Berwick, D., James, B., \& Coye, M. (2003). Connections between quality measurement and improvement. Medical Care, 41(1 Suppl), I30-I38.

Centers for Medicare and Medicaid Services. (2008). Medicare takes new steps to help makeyour hospital stay safer. Retrieved from https:/ /www.cms.gov/Newsroom/MediaReleaseDatabase/ Fact-sheets/2008-Fact-sheets-items / 2008-08-045.html

Centers for Medicare and Medicaid Services (CMS). (2017a). Core measures. Retrieved from https:/ / www.cms.gov/Medicare/Quality-Initiatives-Patient-Assessment-Instruments / QualityMeasures/Core-Measures.html 
Centers for Medicare and Medicaid Services (CMS). (2017b). Hospital compare. Retrieved from https://www.cms.gov/medicare/quality-initiatives-patient-assessment-instruments / hospitalqualityinits/hospitalcompare.html

Committee on the Quality of Health Care in America. (2001). Crossing the quality chasm: A new health system for the 21st century. Washington, DC: National Academy Press.

The Commonwealth Fund. (2014). Mirror, mirror on the wall, 2014 update: How the U.S. health care system compares internationally. Retrieved from http:/ /www.commonwealthfund.org/ publications/fund-reports/2014/jun/mirror-mirror

The Commonwealth Fund. (2017). U.S. health care from a global perspective. Retrieved from http:/ / www.commonwealthfund.org/publications/issue-briefs/2015/oct/us-health-carefrom-a-global-perspective

Dolansky, M. A., \& Moore, S. M. (2013). Quality and safety education for nurses (QSEN): The key is systems thinking. The Online Journal of Issues in Nursing, 18, 3. Retrieved from http:/ / www.nursingworld.org/Quality-and-Safety-Education-for-Nurses.html

Food and Drug Administration (FDA), U.S. Department of Health and Human Services. (2016). What is a serious adverse event? Retrieved from https://www.fda.gov/safety/medwatch/ howtoreport/ucm053087.htm

Food and Drug Administration (FDA), U.S. Department of Health and Human Services. (2017). What we do. Retrieved from https:/ / www.fda.gov /aboutfda/whatwedo

Gawande, A. (2011). The checklist manifesto: How to get things right. New York, NY: Picador.

Glassdoor. (2017). Salary.com Salaries. Retrieved from https://www.glassdoor.com/Salary/ Salary-com-Salaries-E35301.htm

The Health Foundation. (2015). Focus on: International comparisons of healthcare quality. Retrieved from http:/ / www.qualitywatch.org.uk/content/focus-on-international-comparisons-healthcare-quality\#

Healthcare Financial Management Association (HFMA). (2015). Value in health care: Current state and future directions. Westchester, IL: Healthcare Financial Management Association. Retrieved from http:/ /www.hfma.org/Content.aspx?id=1126

HIMSS. (2017). 2017 nursing informatics workforce survey executive summary. Retrieved from http:/ / www.himss.org/library/2017-nursing-informatics-workforce-survey-executive-summary

Institute for Healthcare Improvement. (2017a). Transforming care at the bedside. Accessed at http://www.ihi.org/Engage/Initiatives/Completed/TCAB/Pages/default.aspx

Institute of Medicine (IOM). (1999). In Kohn L. T., Corrigan J. M., and Donaldson M. S. (Eds.), To err is human: Building a safer health system. Washington, DC: National Academy Press. Retrieved from https://www.nap.edu/read/9728/chapter/1

Institute of Medicine (IOM). (2001). In Kohn L. T., Corrigan J. M., and Donaldson M. S. (Eds.), To err is human: Building a safer health system. Washington, DC: National Academy Press. Retrieved from https://www.nap.edu/read/9728/chapter/1

Institute of Medicine (IOM). (2010). The future of nursing: Leading, changing, advancing health. Retrieved from https://www.nursingworld.org/practice-policy/iom-future-of-nursing-report/

Institute of Medicine (IOM). (2015). Assessing progress on the IOM report the future of nursing. Washington, DC: National Academy Press. Retrieved from http://www.nationalacademies.org/hmd/Reports/2015/Assessing-Progress-on-the-IOM-Report-The-Future-ofNursing.aspx

The Joint Commission (TJC). (2015). The cost of Joint Commission Home Care Accreditation. Retrieved from https://www.jointcommission.org/the_cost_for_joint_commission_home_ care_accreditation/

The Joint Commission (TJC). (2017a). Initiatives. Transforming care at the bedside. Retrieved from http://www.ihi.org/Engage/Initiatives/Completed/TCAB/Pages/default.aspx

The Joint Commission (TJC). (2017b). Facts about patient safety. Retrieved from https:// www.jointcommission.org/facts_about_patient_safety/

The Joint Commission (TJC). (2017c). Facts about hospital accreditation. Retrieved from https:// www.jointcommission.org/facts_about_hospital_accreditation

Joint Commission International. (2017). International patient safety goals. Retrieved from http:// www.jointcommissioninternational.org/improve/international-patient-safety-goals/

Leape, L. (2010). Transparency and public reporting are essential for a safe health care system. Perspectives on Health Reform. The Commonwealth Fund. Retrieved from http:// 
www.commonwealthfund.org/publications / perspectives-on-health-reform-briefs/2010/ $\mathrm{mar} /$ transparency-and-public-reporting-are-essential-for-a-safe-health-care-system

The Leapfrog Group. (2017). Never events. Retrieved from http://www.leapfroggroup.org/ influencing/never-events.

The Leapfrog Group. (2017). Reports on hospital performance. Retrieved from http://www. leapfroggroup.org/ratings-reports/reports-hospital-performance

Makary, M. A., \& Daniel, M. (2016). Medical error-the third leading cause of death in the US. BMJ, 353, i2139. doi:10.1136/bmj.i2139

Marsa, L. (2017, September). Take charge of your health care: How to research a surgeon (p. 20) Retrieved from https:/ / www.aarp.org/health/conditions-treatments/info-2017/choose-a-surgeon-doctor-surgeries.html

McCue, M. (2003). Clamping down on variation. Managed Health Care Executive. Retrieved from http:/ / managedhealthcareexecutive.modernmedicine.com/managed-healthcareexecutive/content/clamping-down-variation?page=full

McHugh, M. D., Hawkins, R. E., Mazmanian, P. E., Romano, P. S., Smith, H. L., \& Spetz, J. (2014). Challenges and opportunities in nurse credentialing research design. Institute of Medicine of the National Academies. Retrieved from https://nam.edu/wp-content/uploads/2015/06/ CredentialingResearchWashington, DCDesign.pdf,

Mello, M. M., Chandra, A., Gawande, A. A., \& Studdert, D. M. (2010). National costs of the medical liability system. Health Affairs, 29(9), 1569-1577, doi:10.1377/hlthaff.2009.0807

Mello, M. M., Studdert, D. M., Thomas, E. J., Yoon, C. S., \& Brennan, T. A. (2007). Who pays for medical errors? An analysis of adverse event costs, the medical liability system, and incentives for patient safety improvement. Journal of Empirical Legal Studies, 4(4), 835-860.

Modern Healthcare. Technology price index. Retrieved from http://www.modernhealthcare. com/section/technology-price-index

The Motley Fool. (2017). 5 drugs that are way cheaper in Canada. Retrieved from https:// www.fool.com/investing/2017/01/21/5-drugs-that-are-way-cheaper-in-canada.aspx

Mumford, V., Greenfield, D., Hogden, A., Forde, K., Westbrook, J., \& Braithwaite, J. (2015). Counting the costs of accreditation in acute care: an activity-based costing approach. $B M J$ Open, 5(9), e008850. doi: 10.1136/bmjopen-2015-008850

National Committee for Quality Assurance (NCQA). (2017). HEDIS ${ }^{\circledR}$ measures. Retrieved from http://www.ncqa.org/hedis-quality-measurement/hedis-measures

National Institute of Standards and Technology (NIST). (2016). Baldrige performance excellence program. Baldridge award process fees. Retrieved from https://www.nist.gov/baldrige/ baldrige-award/award-process-fees

National Quality Forum (NQF). (2004). National voluntary consensus standards for nursing-sensitive care: An initial performance measure set. Washington, DC: National Quality Forum. Retrieved from https://www.qualityforum.org/Publications/2004/10/National_Voluntary_Consensus_ Standards_for_Nursing-Sensitive_Care_An_Initial_Performance_Measure_Set.aspx

National Quality Forum (NQF). (2017). List of serious reportable events. Retrieved from http:// www.qualityforum.org/Topics/SREs/List_of_SREs.aspx

Needleman, J., Buerhaus, P., Pankratz, V. S., Leibson, C. L., Stevens, S. R., \& Harris, M. (2011). Nurse staffing and inpatient mortality. New England Journal of Medicine, 364, 1037-1045, doi:10.1056/NEJMsa1001025.

Nuckols, T. K., McGlynn, E. A., Adams, J., Julie Lai, J., Go, M. H., Keesey, J., \& Aledort, J. E. (2011). Cost implications to health care payers of improving glucose management among adults with type 2 diabetes. Health Services Research, 46(4), 1158-1179, doi:10.1111/j.1475-6773.2011.01257.x.

Office of the Inspector General (OIG). (2010). Adverse events in hospitals: National incidence among Medicare beneficiaries. Washington, DC: U.S. Department of Health and Human Services. OIE-06-09-00090.

OECD. (2017). OECD health statistics 2017. Retrieved from http://www.oecd.org/els/healthsystems/health-data.htm

Palmieri, P. A., DeLucia, P. R., Ott, T. E., Peterson, L. T., \& Green, A. (2008). The anatomy and physiology of error in adverse healthcare events. In Savage T. \& Ford E. W. (Eds.), Patient safety and health care management, Advances in health care management (Vol. 7, pp. 33-68), West Yorkshire, England: Emerald Publishing Limited. 
Quality and Safety Education for Nurses (QSEN) Institute. (2014). Graduate QSEN competencies. Retrieved from http:/ /qsen.org/competencies/graduate-ksas

Robert Wood Johnson Foundation (RWJF). (2014). Becoming a Magnet hospital can increase revenue, offset costs of achieving Magnet status. Retrieved from http:/ / www.rwjf.org/en/library/articlesand-news/2014/05/becoming-a-magnet-hospital-can-increase-revenue--offset-costs-of.html

Van Den Bos, J., Rustagi, K., Gray, T., Halford, M., Ziemkiewicz, E., \& Shreve, J. (2011). The \$17.1 billion problem: The annual cost of measurable medical errors. Health Affairs, 30(4), 596-603, doi:10.1377/hlthaff.2011.0084.

Weingart, S. N., Wilson, R. M., Gibberd, R. W., \& Harrison, B. (2000). Epidemiology of medical error. Western Journal of Medicine, 172(6), 390-393.

Wilson, R., Harrison, B., Gibberd, R., \& Hamilton, J. (1999). An analysis of the causes of adverse events from the Quality in Australian Health Care. Medical Journal of Australia, 170, 411-415.

Wolf, Z. R., \& Hughes, R. G. (2008). Error reporting and disclosure. In Hughes R. G. (Ed.). Patient safety and quality: An evidence-based handbook for nurses. AHRQ Publication No. 08-0043. Rockville, MD: Agency for Healthcare Research and Quality.

World Health Organization (WHO). (2009). Conceptual framework for the international classification for patient safety. Version 1.1. Final technical report. Retrieved from http:// www.who.int/patientsafety/taxonomy/icps_full_report.pdf

\section{SUGGESTED READINGS}

Dekker, S. (2011). Patient safety: A human factors approach. Boca Raton, FL: CRC Press.

Gawande, A. (2011). The checklist manifesto: How to get things right. New York, NY: Picador.

Haviley, C., Anderson, A., \& Currier, A. (2014). Overview of patient safety and quality of care. In Kelly, P., Vottero, B., \& McAuliffe, C. (2014). Introduction to quality and safety education for nurses: Core competencies. New York, NY: Springer.

Hughes, R. G. (Ed.) (2008). Patient safety and quality. An evidence-based handbook for nurses. Rockville, MD: U.S. Agency for Healthcare Research and Quality (US).

Institute of Medicine (IOM). (2001). In Kohn L. T., Corrigan J. M., \& Donaldson M. S. (Eds.), To err Is Human: Building a safer health system. Washington, DC: National Academy Press. Retrieved from https:/ / www.nap.edu/read/9728/chapter/1

Institute of Medicine (IOM). (2001). Crossing the quality chasm: A new health system for the 21st century. Retrieved from https://www.nap.edu/catalog/10027/crossing-the-quality-chasm-a-newhealth-system-for-the

Institute of Medicine (IOM). (2004). Keeping patients safe: Transforming the work environment of nurses. Washington, DC: National Academy Press. Retrieved from https://www.nap.edu/ catalog/10851/keeping-patients-safe-transforming-the-work-environment-of-nurses

Institute of Medicine (IOM). (2010). The future of nursing: Leading, changing, advancing health. Retrieved from http://iom.edu/Reports/2010/The-Future-of-Nursing-Leading-ChangeAdvancing-Health.aspx

The Commonwealth Fund. (2015). 2015 international profiles of health care systems: Australia, Canada, China, Denmark, England, France, Germany, India, Israel, Italy, Japan, The Netherlands, New Zealand, Norway, Singapore, Sweden, Switzerland, and the United States. Mossialos E., Wenzl M., Osborn R., \& Sarnak D., D (Eds.), The Commonwealth Fund, Pub No. 1857.

The Joint Commission (TJC). (2017). Initiatives. 5 million lives campaign. Retrieved from http:// www.ihi.org/Engage/Initiatives/Completed/5MillionLivesCampaign/Pages/default.aspx

The Joint Commission (TJC). (2017). Initiatives. The IHI triple aim initiative. Retrieved from http:/ / www.ihi.org/Engage/Initiatives/TripleAim/Pages/default.aspx

The Joint Commission (TJC). (2017). Sentinel event policy and procedures. Retrieved from https:/ / www.jointcommission.org/sentinel_event_policy_and_procedures/

Lee, D. S., \& Mir, H. R. (2014, October). Global systems of health care and trauma. Journal of Orthopedic Trauma, 28(Suppl. 10), S8-S10, doi:10.1097/BOT.0000000000000213.

Wachter, R. M. (2012). Understanding patient safety (2nd ed.). New York, NY: McGraw-Hill. 